\title{
Cohabitation and the Future: Guaranteed Survival?
}

\author{
H. E. Baber \\ Department of Philosophy, University of San Diego, 5998 Alcalá Park, San Diego, CA 92110 \\ *Corresponding Author: baber@sandiego.edu
}

Copyright $@ 2014$ Horizon Research Publishing All rights reserved.

\begin{abstract}
In cases of fission, on Lewis' account, distinct individuals share stages prior to fission. There is a sense in which the survival of such 'cohabiting' individuals is guaranteed. Had fission not occurred there would have been a single individual in their place. So if they, those cohabiting individuals, exist they must survive fission. To that extent any concern they might have about whether they will survive fission is unwarranted. But only to that extent. Like cohabitants, we singles are also guaranteed that our lives won't be over until they're over. Singles and cohabitants have the same reason to be sanguine about their futures - and the same reason to be concerned.
\end{abstract}

Keywords Personal Identity, Lewis, Parfit,
Counterparts, Possibility

It's not over until it's over -------Yogi Berra

\section{Singles and Cohabitants}

According to the 'common-sense view, "what matters for personal survival is identity,.Parfit has challenged this view, citing cases in which, though identity is interrupted, we should say that the persons involved nevertheless survive.So, on Parfit's account, if I were to divide into two persons, each psychologically continuous with me now, I should regard this as survival even though I could not, logically, be identical with both of my (distinct) successors.

Considering such puzzle cases of fission, David Lewis has defended the common-sense view of survival as identity by adopting an uncommonsensical account of synchronic identity. On Lewis' account there are, in such a case, two persons involved before as well as after fission.(Lewis, 1976)Prior to fission, these individuals 'cohabit,' that is, share stages.

The puzzle cases of personal identity that Parfit and Lewis consider are supposed to make us reflect on the nature of our concern for our own future survival. Rebecca Roache has argued however that Lewis-style responses to Parfit in defense of the common-sense view fail because, given the character of the persons involved in branching cases, we cannot infer that what matters for their survival is what matters for us. ${ }^{1} \mathrm{We}$ are concerned about our future survival because it is not guaranteed. According to Roach individuals involved in fission cases cannot be concerned about their survival in the way that we are since their survival 'cannot be jeopardized.' As a consequence, she claims, what matters for their survival may not be what matters for us.

People sharing a pre-fission person-stage cannot properly be concerned for their future survival in the way that ordinary people are. Pre-fission stage-sharers, therefore, are not ordinary people. This means that, whilst cohabitation may tell us that pre-fission stage-sharers survive fission, it tells us nothing about the survival of ordinary people.(Roache, 2010: 258-259)

Fission cases, therefore, tell us nothing about what matters for the survival of ordinary who will not be involved in fission or fusion. Ordinary people are concerned about their future survival. This, according to Roache entails that their future survival and demise are both real possibilities, and that they are aware of this: concern for one's future survival, if it could never be jeopardized, would be as misconceived as concern that one's birth date should remain unchanged. (Roache, 2010: 259)

Roache argues that the survival of individuals who undergo fission cannot be jeopardized until after fission and so that they cannot properly be concerned for their future survival in the way that ordinary people are.

I argue that given the criterion for individuating persons and the account of self-interested concern Roach assumes, both ordinary people and those destined to undergo fission are in the same boat. There is a sense in which our survival, like theirs, is guaranteed. But given any reasonable understanding of self-interested concern, neither we, nor they should be sanguine about that. To the extent that we are concerned about our futures and, in particular about our future survival, our concerns are the same as those of

1 I say 'Lewis-style' responses because the line Roach takes could be directed equally well to, e.g. John Perry's response in 'Can The Self Divide?' according to which there are not two but three persons all along in cases of fission. (Perry, 1972) 'Lewis-style' responses to Parfit's challenge defend the 'common-sense' view of survival as identity by multiplying persons involved in the case such at at any time prior to fission (and on Perry's account, after fission as well) there are more persons than meet the eye insofar as there individuals who 'cohabit,' that is, share stages. On all such accounts there is no person who survives as more than one person. Rather there are two or more persons, each of which survives as one and for each of whom what matters for survival is identity. 
individuals who undergo fission.

\section{Guaranteed Survival}

On Lewis' account persons are 'worms'-aggregates of person-stages, which are temporal parts of persons. (Lewis, 1976)In a case of fission, distinct per during persons include shared stages for some part of their careers in the way that overlapping roads haves hared spatial parts for some stretch of their courses. In a case of fission, on his account, there are two persons involved before as well as after branching.

Before fission such 'cohabiting' persons, who share stages, are indistinguishable but nevertheless distinct in virtue of their post-fission histories. Consider $\mathrm{C} 1$ and $\mathrm{C} 2$, cohabiting individuals who prior to fission, at $\mathrm{t} 1$, share a stage $\mathrm{S}$ and whose stages at $\mathrm{t} 2$, after fission, are distinct stages $\mathrm{S} 1$ and $\mathrm{S} 2$ respectively. Strictly speaking neither $\mathrm{C} 1$ nor $\mathrm{C} 2$, nor any of their constituent stages divides. Division, for spatio-temporal individuals, occurs when after occupying a connected region of space, its parts come to occupy disconnected regions. I divide the cake into pieces, which occupy different places; St. Martin divided his cloak and gave half to a beggar. Neither the cake nor the cloak survives division - though their parts survive detachment. Before they were divided, parts of the cake and the cloak, occupied a connected space; afterwards they did not. The cloak did not survive division: tearing it apart produced two pieces of cloth neither of which was a cloak. Less obviously, cutting the cake destroyed it. Cake, the stuff of which cakes are made, was preserved in the separate pieces, but the cake, that particular parcel of stuff, ceased to exist.

It is not this way in cases of personal fission, on Lewis' account. In a case of fission, neither the persons involved nor any of their stages divide. Stages are momentary and so cannot occupy a single, connected region at one time but two separate regions at a later time, since for them there is no later time. So neither $\mathrm{S}$, nor any of the other stages $\mathrm{C} 1$ and $\mathrm{C} 2$ share prior to fission divide. Neither do $\mathrm{C} 1$ or $\mathrm{C} 2$, the persons who undergo fission. Like ordinary people, who do not fission or fuse, $\mathrm{C} 1$ and $\mathrm{C} 2$ are 'worms'-aggregates of I-interrelated stages, where the I relation is the relation in virtue of which stages are temporal parts of the same individual. In cases of fission, on Lewis' account, there are two such individuals involved at all times, neither of which 'becomes two'. Neither $\mathrm{C} 1$ nor $\mathrm{C} 2$ divide: they merely cease cohabiting. Like the pieces of the cake and parts of the cloak, they become detached. But unlike the pieces of cake and parts of the cloak, prior to detachment they did not merely occupy adjacent regions - they wholly occupied the same region. At every such time, every spatial part of one was part of the other. At every time, $t$, prior to fission C1's stage-at- $t=$ C2's stage-at-t, that is, at every such time they shared stages.

Roach argues that such individuals must, logically, survive fission because persons who share such a pre-fission stage, $\mathrm{S}$, 'owe their very existence to the fact that $\mathrm{S}$ fissions: if they exist at all, they survive until after fission.'(Roache,
2010: 261)Now it is misleading to say that $\mathrm{S}$, a shared stage, fissions: as noted, stages cannot themselves divide. S only 'fissions' in the sense that it is I-related to later stages that are not I-related to one another, which is to say, that stage is shared by worms that are distinct in virtue of their divergence at fission. If fission had not occurred, that is if that stage were not I-related stages which were not themselves I-related, then there would have been just one person rather than two people all along. And, Roach notes, that individual would not be either one of the cohabiting individuals involved in the fission case: if fission had not occurred then neither $\mathrm{C} 1$ nor $\mathrm{C} 2$ would have existed at any time either before or after fission. So if $\mathrm{C} 1$ and $\mathrm{C} 2$ exist prior to fission, it follows that they, those very individuals, logically must survive fission. Therefore, Roach writes, their survival, unlike that of ordinary people, 'cannot be jeopardized' - at least not until after fission.

Since this is a hard sell, consider a comparable case. Suppose that, whether rightly or wrongly, you believe in Necessity of Origin. You contemplate with horror the possibility that your parents might not have hit it off-that your mother might have married your father's identical twin. Then the gametes that got together to produce the embryo from which you originated would not have merged. And you would not have existed. There might have been someone very similar to you - indeed, he might have been genetically exactly similar to you. But it would not have been you-at least so you think if you believe in Necessity of Origin. By the same token, Roach suggests, the identity of an individual depends on how things go for her in the future. If fission had not occurred then $\mathrm{C} 1$ and $\mathrm{C} 2$ would not exist. Everything would have looked the same up to a point: there would be an individual who was indistinguishable from the cohabiting $\mathrm{C} 1 / \mathrm{C} 2$ couple. But she would not have been either of them. Fission only occurs if there are survivors, and $\mathrm{C} 1$ and $\mathrm{C} 2$ exist only if fission occurs. So $\mathrm{C} 1$ and $\mathrm{C} 2$ must survive fission.

If we do not find this persuasive, Roache suggests, it is because even though their survival is guaranteed they are not in a position to know that it is. To know they will survive each of them would have to recognize, prior to fission, that she was half of a cohabiting pair of individuals who were then indiscernible rather than a single normal individual. But the individuals, destined to survive as continuer $\mathrm{C} 1$ and continuer $\mathrm{C} 2$, are indiscernible from one another to themselves as well as to 'outsiders': if, prior to fission, I am one of those persons I cannot determine whether I am C, the person who would have existed if fission had not occurred, or $\mathrm{C} 1$ or $\mathrm{C} 2$. So, before fission, I do not have any compelling reason to believe that my survival is guaranteed; even though if fission occurs my survival cannot be jeopardized. Guaranteed survival isn't terribly interesting if one doesn't know about it. Still, the guarantee stands. And, Roache claims, no such guarantee stands for ordinary people.

\section{Counterparts and Possibilities}


On this account, it is not possible for individuals who undergo fission to die prior to fission: their survival is guaranteed. If however we treat possibility in this way we are going to have to restrict possibilities very significantly - and to multiply guarantee. Could a person fail to survive fission? Let us rerun the story from the first person perspective.

Assume the mechanism by which fission occurs is the usual brain-split-and-transplantation scenario. An individual's brain consists of hemispheres $\mathrm{H} 1$ and $\mathrm{H} 2$ transplanted into bodies B1 and B2. If both transplants 'take' then B1-body person is $\mathrm{C} 1$ and $\mathrm{B} 2$-body person is $\mathrm{C} 2$. If however only one transplant, say H1, takes then B1-body person is not $\mathrm{C} 1$, but $\mathrm{C}$ who, unfortunately, survives the transplant operation with just half a brain: fission does not occur! Again, fission does not occur if neither one of the transplants 'take' and $\mathrm{C}$ simply dies in the traditional sense. In either of the latter two scenarios, $\mathrm{C} 1$ and $\mathrm{C} 2$ do not, at any time, exist. So on this account it is impossible for $\mathrm{C} 1$ and $\mathrm{C} 2$ not to survive fission since they exist only at those worlds where fission occurs, that is where the double transplant is successful!

Suppose I am told that I may undergo fission. Should I worry about the prospect of fission? Certainly not. If I do not undergo fission then I have nothing to worry about because it would have been impossible for me to undergo fission. If fission had occurred I would never have existed in the first place so I wouldn't be around to worry about it! There would have been two distinct individuals, indistinguishable from me, in my place - and I have no egoistic concern about their fates, especially since they are mere possibilia. If fission actually does occur then I have even less reason to worry, since in that case I am either $\mathrm{C} 1$ or $\mathrm{C} 2$. I cannot know which of them I am but that hardly matters since the survival of each of them is guaranteed through fission, which occurs only if both survive. In either case, there is no reason to worry about fission: if it doesn't happen, I do not need to worry; if it does, I survive - one way or another.

Such cheerful fatalism is a little too good to be true. On this account, at least when it comes to fission, things cannot go any differently for an individual from the way they go: either I cannot undergo fission, or I must. But things can go differently, we believe, and not only in some general sense: things can go differently for us.The trouble is that the guaranteed survival thesis assumes an account of possibility that takes certain self-ascriptions understood in the loose and popular sense as strictly and philosophically correct. The assumption is that when I say that something could be true of me at some future time I mean that the individual of which it could be true will be in the strictest sense me-and not, e.g., my closest continuer, counterpart, future stage related in the appropriate way to me-now or any other individual that is not in the strictest metaphysical sense me.

On Lewis' account, however, when I consider such future possibilities I am not anticipating the way in which things will go for me in the strictest sense. Rather I am wondering which member of a large family of counterparts at nearby possible worlds I am. Understood in this way I, a person who is not fated to undergo fission, am in the same predicament as $\mathrm{C} 1$ and $\mathrm{C} 2$ in the fission case: I do not know which one of my currently indiscernible counterparts I am. But the field will soon narrow as the future unfolds.

I worry about my forthcoming dental appointment. I need extensive dental work so the possibilities are almost endless. On Lewis' account, there is a legion of counterparts anticipating that appointment, each wondering whoshe is. Speaking with the vulgar I say that I wonder what is going to happen to me. But in the strict and philosophical sense, when we consider the metaphysical machinery under the hood,I am not contemplating alternative futures for myself since, as a strictly world-bound individual, there are not alternative possibilities for me. I am wondering who I am-whether I am the counterpart who gets the root canal, the counterpart who gets the extraction or the counterpart who gets off easy with just a few fillings.

For each of these individuals, que sera sera: their possibilities are restricted and their futures are absolutely guaranteed. If I am one of the lucky individuals who gets off lightly, nothing could have jeopardized my good luck. I will not feel pain because if there were going to be someone in that dental chair who did feel pain; it would not be (in the strict and philosophical sense) me. In this way I am in the same position as cohabitants $\mathrm{C} 1$ and $\mathrm{C} 2$, whose survival through fission cannot be jeopardized.

But I am worried, and have every right to be. I survey that legion of counterparts at nearby possible worlds, all of whom have histories exactly like mine but face radically different dental prospects. I do not know which of those worlds is actual, that is to say I do not know which of those counterparts is me, and that is why I, and other ordinary individuals, worry about our futures. $\mathrm{C} 1$ and $\mathrm{C} 2$ are concerned about their futures for the same reason that I and other ordinary people are. Like me, they worry about who, among a horde of possible individuals, they are. Even though their survival is guaranteed if fission occurs, each wonders whether she is one of the lucky individuals who survive fission or one of the unlucky ones who die. At some worlds fission occurs, and all of her counterparts survive. There are other worlds at which fission does not does not occur and $\mathrm{C} 1$ and $\mathrm{C} 2$ have just one counterpart between them. At some of these worlds their counterparts live ordinary lives without undergoing any exotic neurosurgical procedures; at others they undergo transplant surgery and come through it with just half a brain; in yet others, the surgery is completely botched and they die. Like me, C1 and C2 worry who they are - and with good reason.

Roach grants that 'there is a sense in which...cohabitants can die before fission...and a sense in which they cannot.'(Roache, 2010: 260)C1 and C2 are vulnerable to fatal mishaps and to that extent could die before fission. But, she notes, there is a sense in which they cannot because 'their doing so is incompatible with certain facts,' viz. the fact that fission will occur. Given that fact, the cohabitants' survival is guaranteed. But that is just the sense in which lucky dental patients' good luck is guaranteed. In the loose and popular 
sense, arguably the sense that matters when it comes to understanding ordinary people's reasonable concern about their futures, both I and those individuals destined to undergo fission have cause for concern: we do not know what the future will be like, which is to say, we do not know who we are. In any case, whether or not the loose and popular sense is what counts for understanding concern about the future, on Lewis' account cohabiting individuals and ordinary people are in the same boat. Either we should both worry or neither of us should.

\section{Identity and the Problem of the Many: We are All Cohabitants Now}

Maybe we should regard this result as a defect of Lewis' counterpart theory - one more reason for the incredulous stare. It might be suggested that counterpart theory undermines the possibility of genuinely self-interested concern about the future, since on this account people never really wonder what will happen to them but rather, strictly and philosophically speaking, wonder which, of a range of counterparts at nearby possible worlds, they are. Nevertheless, even if we ignore otherworldly counterparts, we all have infinitely many this-worldly counterparts and, like individuals involved in fission cases, though our future survival is guaranteed, we do not know which of them we are.

Suppose, as before, we understand persons as worms rather than stages so that a normal individual is an aggregate of person-stages, the earliest of which occurs at her birth, \pm a few months, and the latest just prior to the time of her death. Consider $\mathrm{C}$, a normal individual who does not undergo either fission or fusion, who lives from $t$ to $t^{\prime}$. Let $C^{*}$ be an individual that coincides with $\mathrm{C}$ from $\mathrm{t}$ to $\mathrm{t}^{*}$, a time earlier than $t^{\prime}$. C is not identical with $C^{*}$, and assuming necessity of identity, $\mathrm{C}$ could not be identical with $\mathrm{C}^{*}$. Here we face the familiar Problem of the Many: what we, speaking with the vulgar, count asjust one person is strictly speaking continuum-many overlapping individuals, including $\mathrm{C}$ and $\mathrm{C}^{*}$, each of which is an aggregate of person-stages. See Figure 1 .

We can avoid gross overpopulation by stipulating that the only persons involved are maximal I-interrelated aggregates of person-stages. In that case, $\mathrm{C}^{*}$ is at best a proto-person: an I-interrelated aggregate of person-stages that would be a person if it were maximal, that is, if there were no additional person-stages that were I-related to any stage it included. If we understand persons in this way then the survival of ordinary persons, like the survival of extraordinary persons involved in fission cases, is guaranteed.

C

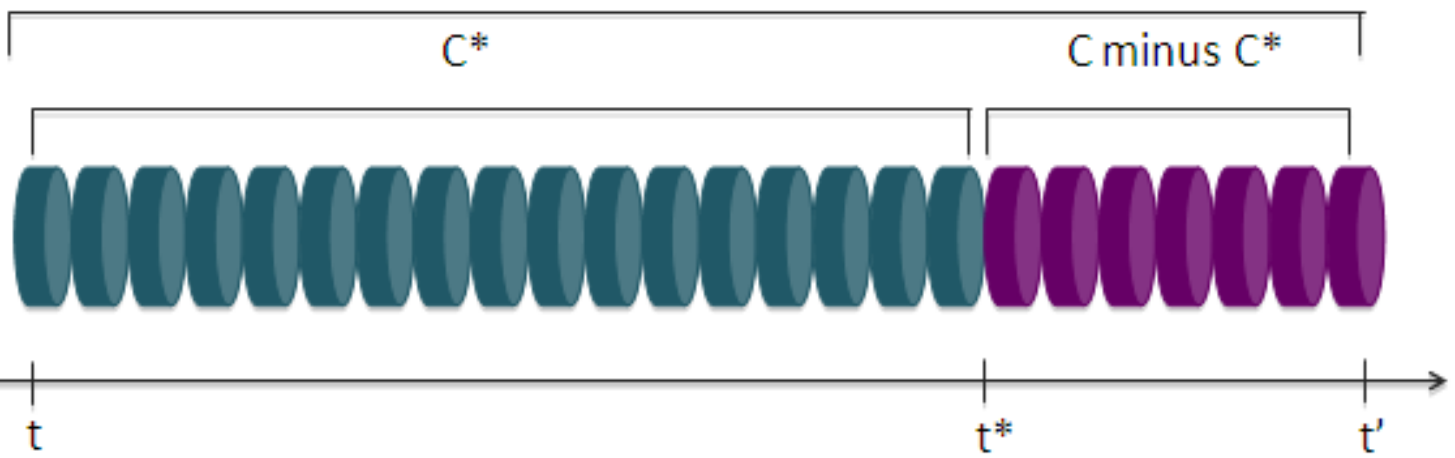

Figure 1. Person-Stages 
If persons are maximal I-interrelated aggregates of stages then ordinary people no less than those extraordinary ones involved in fission and fusion affairs share stages. $2 \mathrm{C}$, an ordinary person, is a cohabitant: she shares stages with $\mathrm{C}^{*}$ and a great many other individuals, though neither $\mathrm{C}^{*}$ nor any of the other individuals with which she shares stages is a person. Could $\mathrm{C}$ have died before $\mathrm{t}^{\prime}$, e.g. at $\mathrm{t}^{*}$ ? Certainly not. Consider $\mathrm{C}$-minus- $\mathrm{C}^{*}$, the aggregate of stages that belong to $\mathrm{C}$ but not to $\mathrm{C}^{*}$. If $\mathrm{C}$ were to die at $\mathrm{t}^{*}$ she would miss out on C-minus- $\mathrm{C}^{*}$ stages. But then her history would include all and only those stages that belonged to $\mathrm{C}^{*}$. That is to say, $\mathrm{C}$ and $\mathrm{C}^{*}$ would consist of exactly the same parts, and so $\mathrm{C}$ would be $\mathrm{C}^{*}$. But that is impossible! $\mathrm{C}^{*}$ is a proper part of $\mathrm{C}$ and so $\mathrm{C}^{*}$ is not identical to $\mathrm{C}$ - and by necessity of identity, cannot be. So $\mathrm{C}$ cannot die at $\mathrm{t}^{*}$ ! And since $\mathrm{t}^{*}$ is arbitrarily chosen, the same will go for any time between $t$ and $t^{\prime}$. C's survival to $t^{\prime}$ is therefore guaranteed in just the way and for just the same reasons that the survival of $\mathrm{C} 1$ and $\mathrm{C} 2$ through fission is guaranteed! Stuff happens, and it is possible that some person who shares initial stages with $\mathrm{C}$ die before t', that is, one of the I-interrelated aggregates of stages that overlaps $\mathrm{C}$ could be maximal. But that individual wouldn't be C.

$\mathrm{C}$, of course, is ignorant: she does not know whether sheis $\mathrm{C}$, or $\mathrm{C}^{*}$ or any one of the other overlapping worms that share stages with her. Individuals who undergo fission are in the same predicament. Before fission, $\mathrm{C} 1$ and $\mathrm{C} 2$ do not know that they are cohabiting and, even if they could be convinced that they had an opposite numbers, they could not know which of the couple they were. Nevertheless, in both the fission case and the non-fission case, survival is guaranteed - for all that is worth. If something had happened to result in the death of an individual who shared C's stages up to $t^{*}$ then $\mathrm{C}$ would not have existed in the first place: if she exists then her survival through $\mathrm{t}^{*}$ and, indeed, her survival to $\mathrm{t}^{\prime}$, is guaranteed. Likewise, if the transplant operation had been botched then $\mathrm{C} 1$ and $\mathrm{C} 2$ would not have existed. If $\mathrm{C} 1$ and $\mathrm{C} 2$ should not worry about surviving fission because their future is guaranteed, then neither should $\mathrm{C}$, since her survival to $\mathrm{t}^{\prime}$ is guaranteed. But Chas the very same reason to be concerned about the future that you and I do. We are all of us aggregates of overlapping proto-persons, some short-lived, others long-lived and each of us worries, with good reason, about which of these individuals we are. And $\mathrm{C} 1$ and $\mathrm{C} 2$ should worry too.

\section{Conclusion}

Roach claims that unlike individuals involved in fission cases, ordinary people 'do not have the luxury of knowing that their survival is guaranteed until some future time.' I have argued that, on the contrary, we do have that luxury - we just do not know what that future time is. And neither do individuals involved in fission cases. We are in the

2 And, of course, individuals involved in fission share infinitely many stages both before and after fission. same boat. In the strict and philosophical sense our survival, like theirs, is guaranteed so their concern about their future survival is all of a piece with our concern about our future survival. Nevertheless, in both ordinary and extraordinary cases individuals may be properly concerned about which people they are.

We ordinary people have no more or less reason to worry about our survival than do individuals who undergo fission. Roach has not succeeded in driving the wedge between ordinary people and the characters in puzzle cases of fission. Whether we are ordinary people or fission cohabitants, it's not over until it's over: our survival until death is guaranteed.

\section{REFERENCES}

[1] Andra, L. (2007). Multiple occupancy, identity, and what matters. Philosophical Explorations, 10(3), 211 - 225.

[2] Brueckner, A., \& Buford, C. T. (2008). The Psychological Approach to Personal Identity: Non-Branching and the Individuation of Person Stages. Dialogue, 47(02), 377-.

[3] Brueckner, A. L. (2005). Branching in the psychological approach to personal identity. Analysis, 65(288), 294-301.

[4] Burke, M. B. (1980). Cohabitation, stuff and intermittent existence. Mind, 89(355), 391-405.

[5] Ehring, D. E. (1995). Personal identity and the r-relation: Reconciliation through cohabitation. Australasian Journal of Philosophy, 73(3), 337-346.

[6] Ehring, D. E. (1999). Fission, fusion, and the Parfit revolution. Philosophical Studies, 94(3), 329-32.

[7] Eklund, M. (2002). Personal identity and conceptual incoherence. Nô̂s, 36(3), 465-485.

[8] Francescotti, R. (2008). Psychological Continuity, Fission, and the Non-Branching Constraint. Pacific Philosophical Quarterly, 89(1), 21-31.

[9] Garrett, B. J. (2004). Johnston on fission. Sorites, 15(December), 87-93.

[10] Gendler, T. S. (2002). Personal identity and thought-experiments. Philosophical Quarterly, 52(206), 34-54.

[11] Hawley, K. (2005). Fission, fusion and intrinsic facts. Philosophy and Phenomenological Research, 71(3), 602-621.

[12] Johansson, J. (2010). Roache's Argument against the Cohabitation View. Philosophia. doi:10.1007/s11406-010-9270-9

[13] Langford, S. (2010). Reply to Roache. Analysis, 70(4), 676-681. doi:10.1093/analys/anq068

[14] Langford, Simon. (2007a). How to defend the cohabitation theory. Philosophical Quarterly, 57(227), 212-224.

[15] Langford, Simon. (2007b). How to defend the cohabitation theory. The Philosophical Quarterly, 57(227), 212-224. doi:10.1111/j.1467-9213.2007.480.x 
[16] Lewis, D. (1976). Survival and identity. In A. O. Rorty (Ed.), The Identities of Persons (pp. 17-40). University of California Press.

[17] Merricks, T. (1997). Fission and personal identity over time. Philosophical Studies, 88(2), 163-186.

[18] Mills, E. O. (1993). Dividing without reducing: Bodily fission and personal identity. Mind, 102(405), 37-51.
[19] Roache, Rebecca. (2010). Fission, cohabitation and the concern for future survival. Analysis, 70(2), 256-263.

[20] Runggaldier, E. (1998). Sortal continuity of material things. Erkenntnis, 48(2-3), 359-369. 